\title{
Microinjection of Different Doses of Corticotropin-releasing Factor into the Medial Prefrontal Cortex Produces Effects Opposing Anxiety-related Behavior in Rats
}

\author{
Hisayuki Ohata and Tamotsu Shibasaki \\ Department of Physiology, Nippon Medical School
}

\begin{abstract}
Corticotropin-releasing factor (CRF) in the medial prefrontal cortex (mPFC) is suggested to play an important role in mediating fear, anxiety, and depression. The results of the studies of the actions of $\mathrm{CRF}$ in the $\mathrm{mPFC}$ regarding anxiety-related behavior, however, seem contradictory. In one study, microinjection of $\mathrm{CRF}$ into the $\mathrm{mPFC}$ produced an increase in anxiety-related behavior on the elevated plus maze, whereas in another study CRF produced an anxiolytic-like effect. To test whether the different doses of CRF used in these experiments are responsible for the differing results, we examined the dose-dependent effects of CRF $(0.015$, $0.05,0.15,0.5$, and $1.0 \mu \mathrm{g} / 0.5 \mu \mathrm{L} /$ site) microinjected into the bilateral $\mathrm{mPFC}$ of male Wistar rats on anxiety-related behavior in the elevated plus maze. We found that microinjection of $0.05 \mu \mathrm{g}$ $\mathrm{CRF}$ significantly decreased the number of open-arm entries, whereas $1.0 \mu \mathrm{g}$ CRF significantly increased the time spent on the open arms. The results indicate that CRF has effects opposing anxiety-related behavior in the elevated plus maze: anxiety-related behavior at a lower dose and an anxiolytic-like effect at a higher dose.
\end{abstract}

(J Nippon Med Sch 2011; 78: 286-292)

Key words: corticotropin-releasing factor, anxiety, medial prefrontal cortex

\section{Introduction}

Corticotropin-releasing factor $(\mathrm{CRF})$ is an important neuropeptide in mediating the behavioral and physiological responses to stress $^{1}$. Central administration of $\mathrm{CRF}$ induces various responses similar to those observed in stressed animals. The peptide exerts its biological actions through 2 types of receptors, $\mathrm{CRF}_{1}$ and $\mathrm{CRF}_{2}$, which have different physiological properties and expression patterns ${ }^{2-5}$.
The CRF receptors are expressed in the medial prefrontal cortex (mPFC), lateral septum, specific amygdala nuclei, and the hippocampus ${ }^{6}$, and these regions are thought to comprise the limbic stress circuits $^{7}$. Immunohistochemical studies have revealed that $\mathrm{CRF}$ is present in the $\mathrm{mPFC}^{8,9}$ and that $\mathrm{CRF}$ is expressed in glutamate decarboxylase-positive interneurons in the rat cerebral cortex ${ }^{10}$. Studies using in situ hybridization have shown that $\mathrm{CRF}_{1}$ receptors are expressed at high levels in the $\mathrm{mPFC}^{3,11}$.

Correspondence to Hisayuki Ohata, PhD, Department of Physiology, Nippon Medical School, 1-1-5 Sendagi, Bunkyoku, Tokyo 113-8602, Japan

E-mail: h_ohata@nms.ac.jp Journal Website (http://www.nms.ac.jp/jnms/) 
Human and primate studies suggest that the CRF system in the mPFC plays an important role in mediating fear, anxiety, and depression ${ }^{12-14}$. An electrophysiological study has shown that preincubation of PFC tissue from normal rats with CRF or pre-exposure of rats to stressors alters 5hydroxytryptamine (5-HT) regulation of gamma aminobutyric acid (GABA) transmission on pyramidal neurons in the $\mathrm{PFC}^{15}$. These results suggest that CRF alters the actions of 5-HT in mediating stress responses. A recent study of the action of CRF on anxiety-related behavior in the $\mathrm{mPFC}$ has found that microinjection of CRF (20 ng) into the $\mathrm{mPFC}$ of stressed rats increases anxietyrelated behavior in the elevated plus maze ${ }^{16}$. On the other hand, another study has shown that microinjection of CRF (200 ng) into the frontal cortex produces anxiolytic-like behavior in unstressed rats ${ }^{17}$. A plausible explanation for the discrepancy between these studies is a difference in the CRF doses used. The issue of the CRF doses has often been examined in functional studies of CRF in the brain ${ }^{1}$. More detailed investigations are needed to clarify the action of CRF in the mPFC.

In the present study, to clarify the dose-dependent effects of CRF in the $\mathrm{MPFC}$ on anxiety-related behavior, we performed behavioral tests with the elevated plus maze after microinjecting different doses of $\mathrm{CRF}$ into the $\mathrm{mPFC}$ of rats.

\section{Materials and Methods}

\section{Subjects}

All experimental procedures were approved by the Animal Care and Use Committee of Nippon Medical School (Approval H21-112, H22-098). Male Wistar rats were obtained from Japan Laboratory Animal, Inc (Tokyo, Japan). The body weights at the time of surgery were 250 to $310 \mathrm{~g}$. Animals were housed individually in cages $(30 \times 20 \times 18 \mathrm{~cm})$ under standard laboratory conditions and maintained in a 12-hour light/dark cycle (lights were on from $8: 00$ a.m. to $8: 00$ p.m.) and allowed ad libitum access to food pellets and water.

\section{Surgical Procedures}

Rats were anesthetized with intraperitoneal injections of sodium pentobarbital $(50 \mathrm{mg} / \mathrm{kg}$; Dainippon Sumitomo Pharma, Osaka) and placed in a stereotaxic apparatus (Narishige, Tokyo). A stainless steel guide cannula (26 gauge) was stereotaxically implanted $1 \mathrm{~mm}$ above the $\mathrm{mPFC}$ bilaterally and secured to the skull using 3 screws and acrylic dental cement. Stereotaxic coordinates, as determined with an atlas of the rat brain $^{18}$, were $\mathrm{AP}=+2.2 \mathrm{~mm}$ from bregma; $\mathrm{L}= \pm 0.5 \mathrm{~mm}$ from medial suture; and $\mathrm{V}=-3.0$ from dura. Dummy stylets were inserted into the guide cannula. After surgery, rats were individually housed and allowed to recover for 5 to 7 days.

\section{Infusion Procedures}

Ovine CRF (Peptide Institute, Inc., Osaka) was dissolved in sterile saline just before the experiment. After stylets were removed, a sample-filled stainlesssteel injection needle (outer diameter, $200 \mu \mathrm{m}$ ) was inserted into the guide cannula so that the injector tip protruded $1 \mathrm{~mm}$ beyond the cannula tip. Solutions of ovine CRF $(0.015,0.05,0.15,0.5$, and 1.0 $\mu \mathrm{g} / 0.5 \mu \mathrm{L} /$ site) or sterile saline as a control was bilaterally microinjected through the injection needle, which was connected through polyethylene tubing to a $10-\mu \mathrm{L}$ microsyringe (701NSR, Hamilton, Reno, NV, USA) mounted on a syringe pump (Nihon Kohden, Tokyo). The solution was delivered at a flow rate of $0.1 \mu \mathrm{L} /$ minute for 5 minute. During the injection procedure, all rats were permitted to behave freely in the gray box $(13 \times 25 \times 35 \mathrm{~cm})$. After the injection, the injectors were kept in the guide cannula for 1 minute before being removed.

\section{The Elevated Plus Maze Test}

Immediately after the injection, rats were moved to the experiment room and kept there for 10 to 15 minute to calm down. Then rats were tested on the plus maze elevated $63 \mathrm{~cm}$ above the floor. The plus maze consisted of 4 arms ( 2 open arms without walls and 2 arms enclosed by 40-cm-long black walls) 50 $\mathrm{cm}$ long and $11 \mathrm{~cm}$ wide, arranged so that arms of the same type were opposite each other, connected by an open central area $(11 \times 11 \mathrm{~cm})$. To prevent 


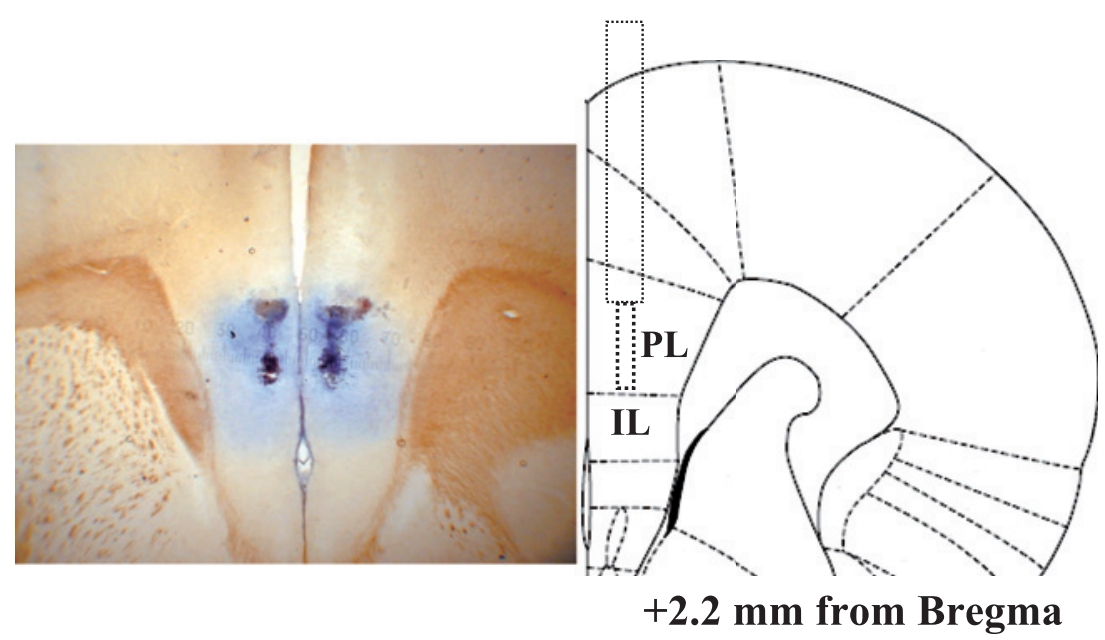

Fig. 1 A representative photomicrograph of a rat coronal section showing the placement of injector tips into the $\mathrm{mPFC}$.

Blue dye, $0.5 \mu \mathrm{L} /$ site, was injected immediately after experimentation, and the positions of injector tips were verified to be within the prelimbic cortex (PrL) or infralimbic are (IL).

rats from falling off, both sides of the open arms were equipped with rims of white plastic $(0.5 \mathrm{~cm}$ high). The open arms and enclosed arms were illuminated with 2 small lights fixed on the ceiling at approximately 22 lux and 5 lux, respectively. At the beginning of each session, rats were placed in the center of the maze facing an open arm and allowed to explore the maze for 5 minute. The animals' behavior was recorded with a camera placed above the maze and connected to a computer. After each trial, the maze was thoroughly cleaned with $70 \%$ ethanol. Using TopScan software (CleverSys, Inc. Reston, VA, USA), the following data were collected: time spent and number of entries in the open or enclosed arms. An entry was defined only when both the center of the animal's body and the base of the tail entered a designated arm.

\section{Cannula Location}

At the end of the experiment, all rats were deeply anesthetized with sodium pentobarbital and received microinjections of $0.5 \mu \mathrm{L}$ of Brilliant Blue dye (Tokyo Kasei, Tokyo) through the injector in the same way as in the experiment. Rat's brains were then perfused, stored in $10 \%$ formalin, and cut into coronal sections. The location of the injector tip was examined with an atlas of the rat brain ${ }^{18}$.

\section{Statistical Analysis}

All data are expressed as means \pm SEM. Separate one-way analyses of variance (ANOVAs) were performed to analyze data. Fisher's protected leastsignificant difference (PLSD) post-hoc tests were performed for significant treatment effects relative to control means. The alpha level for statistical significance was $\mathrm{p}<0.05$. Trends towards significance were noted when $\mathrm{p}<0.10$.

\section{Results}

The site of microinjection was considered correct if the tip of the injector had been placed in the mPFC (Fig. 1). The area of blue dye diffusion included the prelimbic subregion and infralimbic subregion. The injection site was correct in 72 of the 82 rats, and data from these rats were subjected to statistical analysis.

One-way ANOVA indicated that microinjections of $\mathrm{CRF}$ into the bilateral $\mathrm{mPFC}$ had significant effects on the percentage of time spent in the open arms $[F(5,66)=3.20 ; \quad p<0.05] \quad$ (Fig. 2A) and the enclosed arms $[\mathrm{F}(5,66)=2.79 ; \mathrm{p}<0.05]$ of the maze (Fig. 2B). Comparisons with vehicle-treated rats revealed that microinjection of $0.05 \mu \mathrm{g} \mathrm{CRF}$ into the bilateral mPFC had a tendency to decrease the time spent in the open arms and that microinjection of $1.0 \mu \mathrm{g} C R F$ 


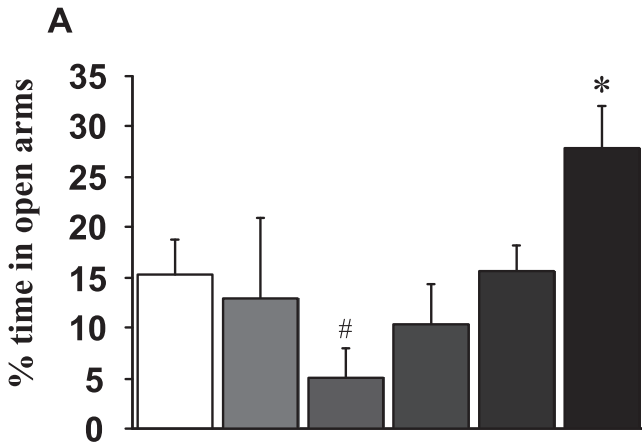

$$
\text { B }
$$

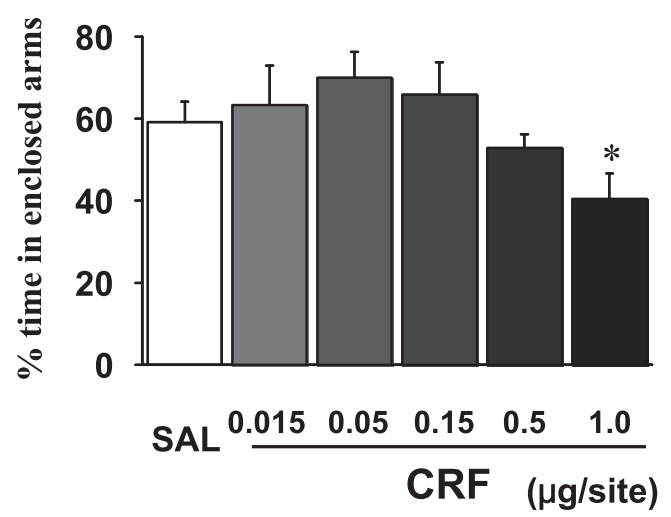

Fig. 2 Effects of microinjection of $\mathrm{CRF}$ into the bilateral $\mathrm{mPFC}$ on the percentage of time spent in the open and enclosed arms of the elevated plus maze.

Each value represents the mean \pm SEM. *Significantly different from vehicle-treated controls $\quad(\mathrm{p}<0.05) . \quad$ \#Trends towards significance from vehicle-treated controls $(\mathrm{p}<0.10)$. SAL, saline-injected group.

significantly increased the time spent in the open arms $(\mathrm{p}<0.05)($ Fig. $2 \mathrm{~A})$ and significantly decreased the time spent in the enclosed arms $(\mathrm{p}<0.05)$ (Fig. 2B).

One-way ANOVA showed that microinjections of $\mathrm{CRF}$ into the bilateral $\mathrm{mPFC}$ had a significant effect on the number of open-arm entries $[F(5,66)=2.63 ; p<$ 0.05]. Comparisons with vehicle-treated rats revealed that microinjection of $0.05 \mu \mathrm{g}$ CRF significantly decreased the number of open-arm entries $(p<0.05)$, whereas microinjection of $1.0 \mu \mathrm{g}$ CRF showed a tendency to increase the number of open-arm entries (Fig. 3A). There was no significant difference in the number of either enclosed-arms entries or total entries (Fig. 3B, C).
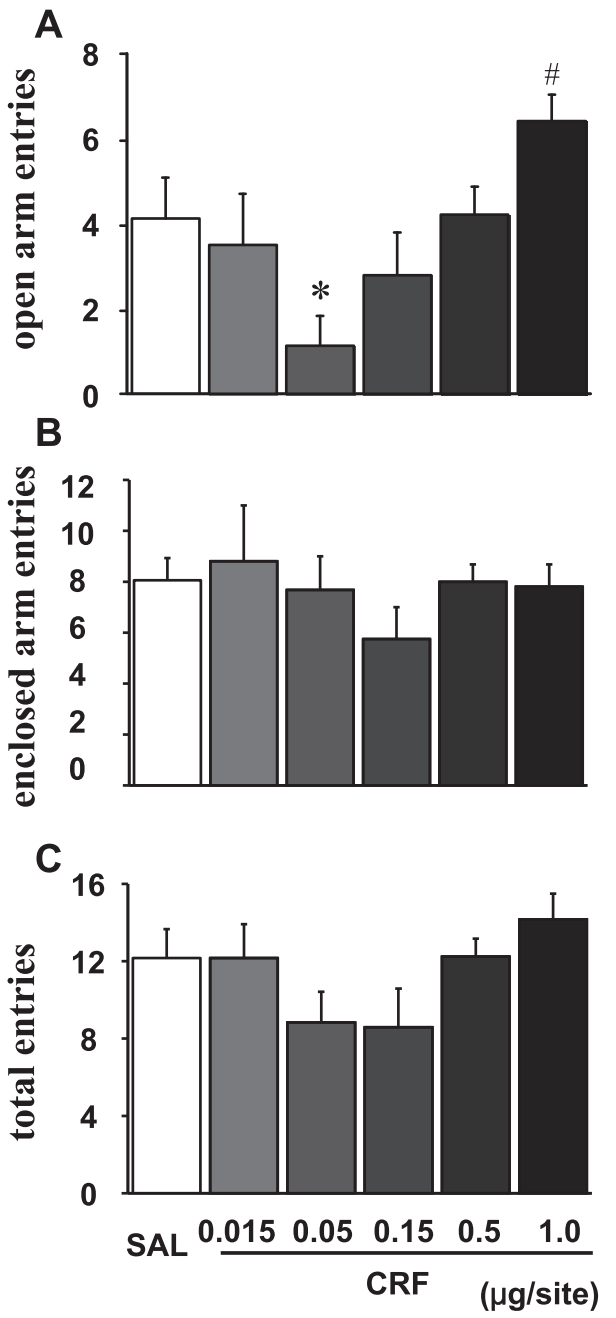

Fig. 3 Effects of microinjection of CRF into the bilateral $\mathrm{mPFC}$ on the number of entries into the open and enclosed arms of the elevated plus-maze and their total numbers. Each value represents the mean \pm SEM. * Significantly different from saline-treated controls $\quad(\mathrm{p}<0.05)$ \#Trends towards significance from vehicle-treated controls $(\mathrm{p}<0.10)$. SAL, saline-injected group.

\section{Discussion}

The elevated plus maze is a popular behavioral test for assessing the anxiety responses of rodents and to investigate both anxiolytic and anxiogenic effects of drugs under identical conditions ${ }^{19}$. In the present study, microinjection of $\mathrm{CRF}$ into the $\mathrm{mPFC}$ dose-dependently decreased and then increased the number of entries or the percentage of time spent in the open arm of the elevated plus maze without changing the total number of entries, which is an 
index of general motor activity ${ }^{20}$. The results suggest that microinjection of $0.05 \mu \mathrm{g} C R F$ into the bilateral $\mathrm{mPFC}$ increases anxiety, whereas microinjection of $1.0 \mu \mathrm{g}$ CRF decreases anxiety.

Previous studies showed that intracerebroventricular injection of CRF or of cortagine, a selective agonist of the $\mathrm{CRF}_{1}$ receptor, significantly decreased general motor activity of rodents and the time spent in the open arm of the elevated plus maze ${ }^{21,22}$. However, in the present study, microinjection of CRF into the mPFC did not change motor activity, as indicated by the total number of entries, suggesting that the effects of microinjecting $\mathrm{CRF}$ into the $\mathrm{mPFC}$ are unlikely to be due to the diffusion of $\mathrm{CRF}$ into the lateral ventricle.

The present study's finding that injection of lowdose CRF $(0.05 \mu \mathrm{g})$ into the mPFC increases anxietyrelated behavior is consistent with a previous report that the microinjection of CRF (20 ng) into the $\mathrm{mPFC}$ of stressed rats increases anxiety-related behavior in the elevated plus maze ${ }^{16}$. Jaferi and Bhatnagar ${ }^{16}$ also found that rats receiving a higher dose of CRF (200 ng) show no substantial difference in the time spent in open arms or in the number of open-arm entries. Their observations were replicated in our experiment, although we performed the elevated plus maze test with unstressed rats. Another study has found that microinjection of CRF $(0.2 \mu \mathrm{g} /$ site $)$ into the frontal cortex produces anxiolytic-like effects in unstressed rats $^{17}$. Our study has also found anxiolytic-like effects of CRF at a higher dose, although we used a higher dose and our injection site was deeper than that of Zieba et $\mathrm{al}^{17}$. In their study, lower doses of CRF (0.1 and $0.05 \mu \mathrm{g}$ ) had no substantial effects on anxietylike behavior in the elevated plus maze. Interestingly, their behavioral assessments in the open field test revealed that CRF at a lower dose $(0.05 \mu \mathrm{g})$ significantly decrease locomotor activity. Although they assessed neither time spent in the central part nor the latency to enter the central part of the open field, the decrease in locomotor activity might be interpreted as an increase in anxiety ${ }^{23}$.

Dunn and Berridge ${ }^{1}$ have reported that the behavioral effects of $\mathrm{CRF}$ at high doses differ from those at low doses. At higher doses CRF decrease feeding and locomotor activity in a novel environment but at lower doses increases feeding and locomotor activity ${ }^{24,25}$. The effects on neuronal activity of local infusion of CRF into the raphe nucleus reportedly differ between high doses and low doses ${ }^{26,27}$. A recent electrophysiological study has revealed that $\mathrm{CRF}$ at low doses activates $\mathrm{CRF}_{1}$ receptors, thereby enhancing GABA activity, which results in the inhibition of 5-HT release, and that $\mathrm{CRF}$ at higher doses acts not only on $\mathrm{CRF}_{1}$ but also on $\mathrm{CRF}_{2}$ receptors of 5 -HT neurons, resulting in the facilitation of 5 -HT release ${ }^{28}$. The finding of the local neuronal mechanism underlying the opposing effect of $\mathrm{CRF}$ in the raphe nucleus suggests the presence of an intrinsic system in the $\mathrm{mPFC}$ in which $\mathrm{CRF}$ has effects opposing anxiety-related behavior.

In the neocortex, $\mathrm{CRF}$ is found in GABA interneurons in layers II and III $^{10,29}$. Such GABA interneurons innervate the pyramidal neurons, in which $\mathrm{CRF}_{1}$ receptors are expressed. Bath application of CRF to slice preparations of cerebral cortex increases the discharge of action potentials of the pyramidal neurons in the presence of blockers for glutamate and GABA transmission, and the activation of the pyramidal neurons is prevented by the selective $\mathrm{CRF}_{1}$ antagonist NBI27914 ${ }^{29}$. This result indicates that the action of CRF on pyramidal neurons is excitatory. On the other hand, CRF has also been shown to enhance the inhibitory action of GABA induced by 5 -HT on the pyramidal neurons ${ }^{10}$. In GABA interneurons of the $\mathrm{mPFC}, 5-\mathrm{HT}_{2 \mathrm{~A}}$ receptors are expressed ${ }^{30}$. A recent study has shown that 5-HT dose-dependently elicits a 5- $\mathrm{HT}_{2 \mathrm{~A}}$-mediated increase in the excitability of GABA interneurons ${ }^{31}$. CRF cosynthesized within GABA neurons reportedly enhances GABAergic inhibition of target neurons through CRF receptors in the central nucleus of the amygdala ${ }^{32}$, the bed nucleus of the stria terminalis ${ }^{33}$, and the dorsal raphe ${ }^{28}$. Therefore, CRF in the mPFC might show a similar effect on the GABAergic inhibition of pyramidal neurons. In the present study, CRF at a dose much higher than that released by 5 -HT in the physiological range might enhance GABAergic inhibition on pyramidal neurons. Because enhancement of GABAergic 
inhibition by infusion of the benzodiazepine midazolam $^{34}$ or muscimol ${ }^{35}$ into the $\mathrm{mPFC}$ produces anxiolytic-like effects on the elevated plus maze, $\mathrm{CRF}$ at a high dose might induce anxiolytic-like effects through the enhancement of GABAergic inhibition.

In pyramidal neurons of the mPFC, $5-\mathrm{HT}_{1 \mathrm{~A}}$ and 5$\mathrm{HT}_{2 \mathrm{~A}}$ receptors are expressed at high levels, and the electrical stimulation of the raphe nucleus elicits 5$\mathrm{HT}_{1 \mathrm{~A}}$-mediated inhibition and 5- $\mathrm{HT}_{2 \mathrm{~A}}$-mediated excitation of pyramidal neurons in the $\mathrm{mPFC}^{36}$. Despite of the opposite effect of 5-HT receptors, 5HT dose-dependently decreases the firing rate of pyramidal neurons ${ }^{31}$. This results suggest that 5$\mathrm{HT}_{1 \mathrm{~A}}$-mediated inhibition is the predominant effect of 5-HT in pyramidal neurons of the PFC. Recently, activation of $\mathrm{CRF}_{1}$ receptor in the $\mathrm{mPFC}$ has been shown to enhance $5-\mathrm{HT}_{2}$ receptor signaling by recruiting $5-\mathrm{HT}_{2}$ receptors to the cell surface, and infusion of $\mathrm{CRF}$ with an 5-HT agonist into the $\mathrm{mPFC}$ has been shown to increase anxiety-related behavior in the open field test and in the elevated plus maze test $^{37}$. These results indicate that CRF increases 5$\mathrm{HT}_{2 \mathrm{~A}}$-mediated excitation of pyramidal neurons in the mPFC. To our knowledge, the involvement of $\mathrm{CRF}$ in the control of $5-\mathrm{HT}_{1 \mathrm{~A}}$ receptors, which are believed to play important roles in anxiety and depression $^{38}$, has never been investigated. Furthermore, a new interaction between CRF and dopamine on glutamate transmission in the mPFC has been reported ${ }^{39}$. Further studies are needed to elucidate the actions of $\mathrm{CRF}$ in the $\mathrm{mPFC}$.

We examined the dose-dependent effects of CRF microinjected into the bilateral $\mathrm{mPFC}$ on anxietyrelated behavior in the elevated plus maze. The results show that $\mathrm{CRF}$ has effects opposing anxietyrelated behavior in the elevated plus maze: anxietyrelated behavior at a lower dose and an anxiolyticlike effect at a higher dose.

Conflict of interest: The authors declare no conflict of interest.

Acknowledgments: This work was supported in part by Health and Labour Sciences Research Grants for Research on Measures for Intractable Diseases (anorexia nervosa).

\section{References}

1. Dunn AJ, Berridge CW: Physiological and behavioral responses to corticotropin-releasing factor administration: is CRF a mediator of anxiety or stress responses? Brain Res Rev 1990; 15: 71-100.

2. Chalmers DT, Lovenberg TW, De Souza EB: Localization of novel corticotropin-releasing factor receptor (CRF2) mRNA expression to specific subcortical nuclei in rat brain: comparison with CRF1 receptor mRNA expression. J Neurosci 1995; 15: 6340-6350.

3. Van Pett K, Viau V, Bittencourt JC, et al.: Distribution of mRNAs encoding CRF receptors in brain and pituitary of rat and mouse. J Comp Neurol 2000; 428: 191-212.

4. Reul JM, Holsboer F: Corticotropin-releasing factor receptors 1 and 2 in anxiety and depression. Curr Opin Pharmacol 2002; 2: 23-33.

5. Ohata H, Shibasaki T: The CRF peptide family in appetite regulation and energy balance. Curr Med Chem Cent Nerv Syst Agents 2003; 3: 243-255.

6. Joëls M, Baram TZ: The neuro-symphony of stress. Nat Rev Neurosci 2009; 10: 459-466.

7. Ulrich-Lai YM, Herman JP: Neural regulation of endocrine and autonomic stress responses. Nat Rev Neurosci 2009; 10: 397-409.

8. Swanson LW, Sawchenko PE, Rivier J, Vale WW: Organization of ovine corticotropin-releasing factor immunoreactive cells and fibers in the rat brain: an immunohistochemical study. Neuroendocrinology 1983; 36: 165-186.

9. Morin SM, Ling N, Liu XJ, Kahl SD, Gehlert DR: Differential distribution of urocortin- and corticotropin-releasing factor-like immunoreactivities in the rat brain. Neuroscience 1999; 92: 281-291.

10. Yan XX, Baram TZ, Gerth A, Schultz L, Ribak CE: Co-localization of corticotropin-releasing hormone with glutamate decarboxylase and calcium-binding proteins in infant rat neocortical interneurons. Exp Brain Res 1998; 123: 334-340.

11. De Souza EB, Insel TR, Perrin MH, Rivier J, Vale WW, Kuhar MJ: Corticotropin-releasing factor receptors are widely distributed within the rat central nervous system: an autoradiographic study. J Neurosci 1985; 5: 3189-3203.

12. Nemeroff CB, Owens MJ, Bissette G, Andorn AC, Stanley M: Reduced corticotropin releasing factor binding sites in the frontal cortex of suicide victims. Arch Gen Psychiatry 1988; 45: 577-579.

13. Kalin NH, Shelton SE, Davidson RJ: Cerebrospinal fluid corticotropin-releasing hormone levels are elevated in monkeys with patterns of brain activity associated with fearful temperament. Biol Psychiatry 2000; 47: 579-585.

14. Merali Z, Du L, Hrdina P, et al.: Dysregulation in the suicide brain: mRNA expression of corticotropinreleasing hormone receptors and $\mathrm{GABA}_{\mathrm{A}}$ receptor subunits in frontal cortical brain region. J Neurosci 2004; 24: 1478-1485.

15. Tan $\mathrm{H}$, Zhong $\mathrm{P}$, Yan $\mathrm{Z}$ : Corticotropin-releasing factor and acute stress prolongs serotonergic regulation of GABA transmission in prefrontal 
cortical pyramidal neurons. J Neurosci 2004; 24: 5000-5008

16. Jaferi A, Bhatnagar S: Corticotropin-releasing hormone receptors in the medial prefrontal cortex regulate hypothalamic-pituitary-adrenal activity and anxiety-related behavior regardless of prior stress experience. Brain Res 2007; 1186: 212-223.

17. Zieba B, Grzegorzewska M, Brański P, et al.: The behavioural and electrophysiological effects of CRF in rat frontal cortex. Neuropeptides 2008; 42: 513523

18. Paxinos G, Watson C: The rat brain in stereotaxic coordinates, 1997; Academic Press, San Diego.

19. Pellow S, Chopin P, File SE, Briley M: Validation of open:closed arm entries in an elevated plus-maze as a measure of anxiety in the rat. J Neurosci Methods 1985; 14: 149-167.

20. Korte SM, De Boer SF, Bohus B: Fear-potentiation in the elevated plus-maze test depends on stressor controllability and fear conditioning. Stress 1999; 3: 27-40.

21. Baldwin HA, Rassnick S, Rivier J, Koob GF, Britton $\mathrm{KT}$ : CRF antagonist reverses the "anxiogenic" response to ethanol withdrawal in the rat. Psychopharmacology 1991; 103: 227-232.

22. Tezval H, Jahn O, Todorovic C, Sasse A, Eckart K, Spiess J: Cortagine, a specific agonist of corticotropin-releasing factor receptor subtype 1 , is anxiogenic and antidepressive in the mouse model. Proc Natl Acad Sci U S A 2004; 101: 9468-9473.

23. Prut L, Belzung C: The open field as a paradigm to measure the effects of drugs on anxiety-like behaviors: a review. Eur J Pharmacol 2003; 463: 3-33.

24. Sutton RE, Koob GF, Le Moal M, Rivier J, Vale W: Corticotropin releasing factor produces behavioural activation in rats. Nature 1982; 297: 331-333.

25. Samarghandian S, Ohata H, Yamauchi N, Shibasaki $\mathrm{T}$ : Corticotropin-releasing factor as well as opioid and dopamine are involved in tail-pinch-induced food intake of rats. Neuroscience 2003; 116: 519-524.

26. Kirby LG, Rice KC, Valentino RJ: Effects of corticotropin-releasing factor on neuronal activity in the serotonergic dorsal raphe nucleus. Neuropsychopharmacology 2000; 22: 148-162.

27. Pernar L, Curtis AL, Vale WW, Rivier JE, Valentino RJ: Selective activation of corticotropin-releasing factor-2 receptors on neurochemically identified neurons in the rat dorsal raphe nucleus reveals dual actions. J Neurosci 2004; 24: 1305-1311.

28. Kirby LG, Freeman-Daniels E, Lemos JC, et al. Corticotropin-releasing factor increases GABA synaptic activity and induces inward current in 5hydroxytryptamine dorsal raphe neurons. J Neurosci 2008; 28: 12927-12937.
29. Gallopin T, Geoffroy H, Rossier J, Lambolez B: Cortical sources of CRF, NKB, and CCK and their effects on pyramidal cells in the neocortex. Cereb Cortex 2006; 16: 1440-1452.

30. Willins DL, Deutch AY, Roth BL: Serotonin $5-\mathrm{HT}_{2 \mathrm{~A}}$ receptors are expressed on pyramidal cells and interneurons in the rat cortex. Synapse 1997; 27: 7982.

31. Zhong P, Yan Z: Differential regulation of the excitability of prefrontal cortical fast-spiking interneurons and pyramidal neurons by serotonin and fluoxetine. PLoS One 2011; 6: e16970.

32. Nie Z, Schweitzer P, Roberts AJ, Madamba SG, Moore SD, Siggins GR: Ethanol augments GABAergic transmission in the central amygdala via CRF1 receptors. Science 2004; 303: 1512-1514.

33. Kash TL, Winder DG: Neuropeptide $Y$ and corticotropin-releasing factor bi-directionally modulate inhibitory synaptic transmission in the bed nucleus of the stria terminalis. Neuropharmacology 2006; 51: 1013-1022.

34. Shah AA, Treit D: Infusions of midazolam into the medial prefrontal cortex produce anxiolytic effects in the elevated plus-maze and shock-probe burying tests. Brain Res 2004; 996: 31-40.

35. Shah AA, Sjovold T, Treit D: Inactivation of the medial prefrontal cortex with the $\mathrm{GABA}_{\mathrm{A}}$ receptor agonist muscimol increases open-arm activity in the elevated plus-maze and attenuates shock-probe burying in rats. Brain Res 2004; 1028: 112-115.

36. Amargós-Bosch M, Bortolozzi A, Puig MV, et al.: Coexpression and in vivo interaction of $\operatorname{serotonin}_{1 \mathrm{~A}}$ and serotonin $_{2 \mathrm{~A}}$ receptors in pyramidal neurons of prefrontal cortex. Cereb Cortex 2004; 14: 281-299.

37. Magalhaes AC, Holmes KD, Dale LB, et al.: CRF receptor 1 regulates anxiety behavior via sensitization of 5-HT2 receptor signaling. Nat Neurosci 2010; 13: 622-629.

38. Savitz J, Lucki I, Drevets WC: $5-\mathrm{HT}_{1 \mathrm{~A}}$ receptor function in major depressive disorder. Prog Neurobiol 2009; 88: 17-31.

39. Orozco-Cabal L, Liu J, Pollandt S, Schmidt K, Shinnick-Gallagher P, Gallagher JP: Dopamine and corticotropin-releasing factor synergistically alter basolateral amygdala-to-medial prefrontal cortex synaptic transmission: functional switch after chronic cocaine administration. J Neurosci 2008; 28: 529-542.

(Received, May 23, 2011)

(Accepted, June 9,2011) 